\title{
Stres u radu fizioterapeuta
}

\author{
${ }^{1,2}$ Aleksandra Kraljević \\ 2 Melita Rukavina \\ 1,2 Nikolino Žura \\ 1 Klinički bolnički centar Zagreb \\ 2 Zdravstveno veleučilište Zagreb
}

\section{Sažetak}

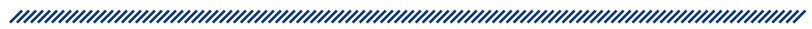

U znanosti, stres se pojavljuje kao predmet istraživanja od tehničkih preko biomedicinskih, društvenih do humanističkih znanosti. Svako ga područje definira na svoj način, pa se u suvremenoj literaturi nalaze mnogobrojne definicije i određenja pojma stresa. Smatra se da je u suvremenom svijetu stres jedan od najvažnijih uzročnika psihofizičkih, radnih i organizacijskih problema zaposlenika. Na drugom je mjestu ljestvice zdravstvenih tegoba zaposlenih u Europskoj uniji, od toga više u žena nego u muškaraca. Jedan je od najvećih uzročnika profesionalnih bolesti i bolovanja u svijetu te je među vodećim gospodarskim problemima u razvijenim zemljama.

Cilj ovog rada bio je utvrditi najčešće izvore stresa u fizioterapeuta te ispitati odnos između stresa i sociodemografskih obilježja ispitanika.

Istraživanje je provedeno na 65 fizioterapeuta zaposlenih u Kliničkom bolničkom centru Zagreb. Prosječna dob ispitanika bila je 42,8 godina. Istraživanje je provedeno primjenom Upitnika o stresorima na radnom mjestu bolničkih zdravstvenih djelatnika.
Rezultati su pokazali da fizioterapeuti procjenjuju potencijalne izvore stresa nisko ili umjereno stresno. Istraživanjem korelacija između varijabli: razina stresa $s$ dobi, ukupnim radnim stažem te radnim stažem na trenutačnom radnom mjestu, nije nađena statistički značajna povezanost.

Možemo zaključiti kako razina stresa u fizioterapeuta u odnosu na sociodemografska obilježja nije statistički značajna. Na skali intenziteta stresa kao najjači su prepoznati oni povezani s organizacijom rada i financijskim ograničenjima, što odgovara i rezultatima istraživanja provedenih u svijetu.

Ključne riječi: stres, stres na radu, fizioterapeuti

Datum primitka: 26.3.2019.

Datum prihvaćanja: 1.7.2019.

DOI: $10.24141 / 1 / 5 / 2 / 11$

Adresa za dopisivanje:

Aleksandra Kraljević, dipl. physioth.

A: KBC Zagreb, Klinika za reumatske bolesti i rehabilitaciju, Kišpatićeva ul. 12, 10000 Zagreb

E-mail: kraljevicaleksandra@gmail.com

T: +385 981762056 


\section{Uvod}

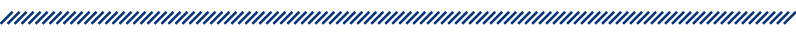

Pojam stres označava stanje organizma u kojem doživljavamo prijetnju vlastitom integritetu, razumljiv je ljudima na različitim jezicima, u različitim kulturama, razumiju ga ljudi različitih dobi i pripadnici različitih skupina. ${ }^{1}$

Riječ stres ima podrijetlo iz srednjovjekovnog engleskog jezika (engl. stress-napor, nevolja ili ograničenost). Upotrebljava se kao pojam već u 14. stoljeću u značenju patnje, muke, neprilike, tegobe, nesreće ili tuge. $U$ 19.stoljeću pojam stresa smatran je temeljem slabog zdravlja te je povezivan s brojnim slučajevima angine pectoris. Početkom 20. stoljeća smatralo se da je stres poremećaj homeostaze do kojeg dolazi zbog hladnoće, pomanjkanja kisika ili sniženog šećera u krvi. Tridesetih godina 20.stoljeća Selye je postavio model fiziološkog stresa i utvrdio kako različiti podražaji izazivaju jednake fiziološke promjene. Podražaje koji uzrokuju stres nazvao je stresori. ${ }^{2}$

Svakako je najpoznatiji i najutjecajniji autor u ovom području američki psiholog Richard Lazarus. Lazarus stres definira kao sustav emocionalnih, tjelesnih i bihevioralnih reakcija do kojih dolazi kada osoba procijeni neki događaj uznemirujućim, odnosno kao niz psihičkih i tjelesnih reakcija na stresor koji pred osobu postavlja zahtjeve kojima ne može udovoljiti. Izvor stresa može biti vanjski događaj ili niz događaja koje osoba procjenjuje ugrožavajućima, a stres je unutrašnje stanje ili doživljaj. Sa stajališta koje zastupa Lazarus, ono što je stresno za jednu osobu u određenom trenutku ne mora biti stresno za drugu osobu ili za istu osobu u nekom drugom trenutku. Lazarusov transakcijski model stresa jedan je od najprihvaćenijih modela stresa, a ubraja se u suvremene transakcijske modele stresa, koji podrazumijevaju uzajamni odnos između pojedinca i njegove okoline, odnosno onoga što se objektivno događa. On je postavio do danas najpoznatiji teorijski model stresa i konstruirao nekoliko psiholoških mjernih instrumenata za dijagnostiku kvalitete i intenziteta doživljaja stresa, te strategija suočavanja. Prema njegovu mišljenju i nalazima, čovjek prolazi kroz tri procesa kada je izložen stresu. $U$ prvoj fazi procjene percipira neku vrstu prijetnje, zatim slijedi proces osvještavanja svih mogućih reakcija na prijetnju i tek nakon toga slijedi reakcija, odnosno neki od mogućih načina suočavanja. Drugim riječima, sam događaj predstavlja samo potencijalni izvor stresa ili stresor, a pojava i intenzitet stresa subjektivno su određeni. Ovise o tome kako osoba percipira situaciju. O stresu govorimo u situaciji kada osoba procjenjuje da postavljeni zahtjevi nadmašuju njezine sposobnosti prilagodbe. $^{3}$

Stres na radu specifična je vrsta stresa čiji je izvor u radnom okolišu. Sedamdesetih godina 20. stoljeća postaje predmet proučavanja liječnika i psihologa, a zadnje desetljeće predstavlja globalni javnozdravstveni problem. ${ }^{4}$

Stanje stresa na poslu može se definirati kao niz za pojedinca štetnih fizioloških, psiholoških i bihevioralnih reakcija na situacije u kojima zahtjevi posla nisu u skladu s njegovim sposobnostima, mogućnostima i potrebama.

Istraživanja pokazuju povezanost stresa i radnog učinka. Ako je stres umjeren, djeluje motivirajuće na zaposlenika i naziva se eustres. Premalen stres povezan je s niskim radnim učinkom. Prevelika količina stresa povezana je s niskim radnim učinkom, a njezin ishod često je povezan s nizom oboljenja kod zaposlenika., 6

Nekoliko vrsta čimbenika prepoznaje se kao uzrok stresa na radnom mjestu, a odnosi se na šest područja organizacije rada, a to su: zahtjevi, kontrole, odnosi, promjene, uloge i podrška. Propusti u njima dovode do kroničnog stresa u zaposlenika i time se ugrožava zdravlje zaposlenika, pada produktivnost, raste broj dana izostanka s posla i smanjuje se osjećaj dobrobiti u zaposlenika. ${ }^{6}$

Stres je na drugome mjestu ljestvice zdravstvenih tegoba zaposlenika u Europskoj uniji i ugrožava 22\% europskih radnika. Stres na radnome mjestu odgovoran je za 50 do $60 \%$ svih izgubljenih radnih dana, što je procijenjeni gubitak od 20 milijardi eura godišnje. ${ }^{7}$

Ako su zaposlenici pod stresom i broj stresora se povećava te se zaposlenik sve teže nosi sa situacijom u kojoj se nalazi nastupa sindrom izgaranja/ sagorijevanja na radu (engl. burn out). Posljedice sagorijevanja na radu očituju se kao gubitak idealizma, energije i smislenosti vlastitog rada te su rezultat frustracija na poslu. Uključuju promjene stavova prema poslu i ponašanja prema korisnicima usluga. Sindrom izgaranja na poslu jedna je od najnepovoljnijih posljedica dugotrajne izloženosti izvorima stresa na radu. ${ }^{8}$

Stres na radu čest je problem u zdravstvenih profesionalaca svih profila. Zaposlenici u zdravstvu kao liječnici, medicinske sestre, fizioterapeuti i druge srodne profesije izloženi su stresnim situacijama na radnom mjestu, a odnose se na rad u emotivno zahtjevnim situacijama povezanima s tjelesnim i psihičkim zahtjevima bolesnika s kojima rade uz ostale organizacijske stresore. 
Fizioterapeuti mogu lako razviti sindrom izgaranja na poslu što može negativno utjecati na kvalitetu skrbi za bolesnika. Produljeni kontakt i kontinuirana skrb za bolesnika mogu biti emocionalno iscrpljujući i veoma stresni za fizioterapeute. ${ }^{9}$

Dostupna istraživanja pokazuju da fizioterapeuti navode dokaze o mogućim stresorima u psihosocijalnom radnom okruženju koji mogu uzrokovati stres na poslu. Ti stresori uključuju percepciju pretjeranih radnih zahtjeva, gubitka kontrole, nedostatka podrške, frustracije $s$ bolesnicima te poteškoća u profesionalnim odnosima. Zaključci iz ovih studija, međutim, ne mogu se primijeniti na sve fizioterapeute jer su zaposleni u različitim radnim okruženjima. Malo je istraživanja istraživalo psihosocijalno radno okruženje za fizioterapeute na nacionalnoj razini. ${ }^{10-13}$

Cilj je ovog istraživanja utvrditi najčešće izvore stresa na poslu fizioterapeuta te ispitati odnos između stresa i sociodemografskih obilježja ispitanika i na temelju dobivenih rezultata izraditi prijedloge preventivnih mjera za ublažavanje stresa.

\section{Metode}

Istraživanje je provedeno među fizioterapeutima koji rade u Kliničkom bolničkom centru Zagreb (KBC Zagreb), u Klinici za reumatske bolesti i rehabilitaciju, Klinici za ortopediju i Kliničkom zavodu za rehabilitaciju i ortopedska pomagala. Istraživanje je provedeno u razdoblju od kolovoza do listopada, 2016. godine, uz odobrenje Etičkog povjerenstva KBC-a Zagreb. Ispitanici su ispunjene Upitnike ostavljali u za to predviđenu kutiju.

Ispitivanjem je obuhvaćeno 65 fizioterapeuta, no 63 (97\%) ispitanika pravovaljano je ispunilo upitnike. Ispitana su tri (5\%) fizioterapeutska tehničara, 55 (87\%) prvostupnika fizioterapije te pet $(8 \%)$ diplomiranih fizioterapeuta.

Od 63 ispitanika bilo je 49 (78 \%) žena, a 14 (22 \%) muškaraca. Prosječna dob ispitanika bila je 42,8 $\pm 11,05$ godina.

Polovica $(50,8 \%)$ ispitanika zaposleni su na radnom mjestu fizioterapeuta na polikliničkim odjelima KBC-a Zagreb, dok je 32\% zaposleno na kliničkim odjelima, a 17,5 $\%$ u jedinicama intenzivnog liječenja (JIL) (tablica 1 ).

\begin{tabular}{|c|c|}
\hline $\begin{array}{c}\text { Tablica 1. Prikaz ispitanika s obzirom na } \\
\text { radno mjesto }\end{array}$ \\
\hline RADNO MJESTO & $\mathrm{N}(\%)$ \\
\hline POLIKLINIKA & $32(50,8)$ \\
\hline KLINIČKI ODJEL & $20(31,7)$ \\
\hline JIL & $11(17,5)$ \\
\hline UKUPNO & $63(100)$ \\
\hline
\end{tabular}

Najveći broj fizioterapeuta (20/63 ispitanika) ima između 26 i 35 godina radnog staža, dok najmanji broj fizioterapeuta (5/63 ispitanika, odnosno 7/63 ispitanika) ima između 36 i 45 godina radnog staža te 6 i 15 godina radnog staža.

Istraživanje je provedeno primjenom standardiziranog upitnika. Upitnik o stresorima na radnom mjestu bolničkih zdravstvenih djelatnika, autora Milana Miloševića. ${ }^{14}$ Za potrebe ovog istraživanja modificiran je Upitnik o stresorima na radnom mjestu bolničkih zdravstvenih djelatnika (Upitnik), kojim smo ispitivali 33 stresora od ponuđenih 37 . Većina ispitanika nije odgovorila na tvrdnje stresora od rednog broja 3. do 6. Navedene tvrdnje odnose se na organizacijski model rada kojemu fizioterapeuti nisu izloženi (noćni rad, dežurstava, smjenski rad, prekovremeni rad) te navedene tvrdnje nismo statistički obradili.

Prvi dio Upitnika sastoji se od općih sociodemografskih podataka: spol, dob, bračno stanje, stupanj obrazovanja, radno mjesto, duljina ukupnoga radnog staža, duljina radnog staža na sadašnjem radnom mjestu. Drugi dio Upitnika sastoji se od pitanja o stresorima na radnom mjestu. Pitanja o stresorima podijeljena su u šest kategorija. Prva kategorija odnosi se na organizaciju rada i financije, druga kategorija odnosi se na javnu kritiku i sudske tužbe, treća kategorija odnosi se na strah od opasnosti i štetnosti u zdravstvu, četvrta kategorija odnosi se sukobe i komunikaciju na poslu, peta kategorija odnosi se na smjenski rad (nismo ispitivali u ovom istraživanju), a šesta kategorija odnosi se na profesionalne i intelektualne zahtjeve. Ispitanici su doživljaj stresora ocjenjivali na Likertovoj ljestvici ocjenama od 1 do 5 (1 = nije stresno, 2 = rijetko stresno, 3 = ponekad stresno, 4 $=$ stresno, 5 = izrazito stresno). ${ }^{14}$

Opći podaci prikazani su deskriptivnom statističkom metodom (aritmetička sredina i standardna devijacija) te su razlike među skupinama ispitane t- testom, a rezultat za doživljaj stresa prikazan je kao prosječna vrijednost po pojedinim tvrdnjama izvora stresa. Za testiranje razlika i odnosa među pojedinim varijablama 
upotrjebljeni su parametrijski postupci jer je Kolmogorov-Smirnovljev test pokazao da distribucija intenziteta stresa s obzirom na ispitivane nezavisne varijable statistički značajno ne odstupa od normalne distribucije.

\section{Rezultati}

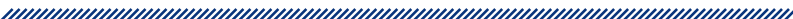

Prema upitniku Stres na radnom mjestu bolničkih zdravstvenih djelatnika, prosječni ukupni doživljaj stresa za promatranu skupinu ispitanika bio je ispod prosjeka, odnosno 2,7 (tablica 2).

\begin{tabular}{|c|c|c|c|c|}
\hline & $\mathrm{N}$ & MIN & MAKS. & $\mathrm{M} \pm \mathrm{SD}$ \\
\hline STRES & 63 & 1,21 & 4,42 & $2,71 \pm 0,72$ \\
\hline
\end{tabular}

Prosječna razina stresa ukazuje da fizioterapeuti procjenjuju potencijalne izvore stresa nisko ili umjereno stresno. Prosječna razina stresa između muškaraca i žena vrlo je slična (tablica 3) te iako postoji trend veće razine stresa kod žena, navedena razlika nije statistički značajna ( $t=-1,931 ; p=0,058)$.

\begin{tabular}{|c|c|c|c|}
\hline & SPOL & $\mathrm{N}$ & $\mathrm{M} \pm \mathrm{SD}$ \\
\hline STRES & ŽENE & 49 & $2,80 \pm 0,71$ \\
\hline STRES & MUŠKARCI & 14 & $2,38 \pm 0,70$ \\
\hline
\end{tabular}

Nema statistički značajne razlike u razini stresa s obzirom na radno mjesto $(F=0,321 ; p=0,727)$.

Istraživanjem linearnih korelacija između varijabli: razina stresa s dobi, ukupnim radnim stažem te radnim stažem na trenutačnom radnom mjestu, nije nađena statistički značajna povezanost $\left(\mathrm{p}^{1}=0,25, \mathrm{p}^{2}=0,18, \mathrm{p}^{3}=\right.$ 0.45), (tablica 4).
Tri najveće prosječne vrijednosti stresa po pojedinim tvrdnjama odnose se na: 1 . nedostatan broj djelatnika ( $M$ $=3,94), 2$. administrativne poslove $(M=3,76)$, 3. neadekvatna osobna primanja $(M=3,73)$, dok se tri najmanje prosječne vrijednosti odnose se na; 1. 24-satnu odgovornost $(M=1,65), 2$. strah od izloženosti citostaticima ( $M=$ 1,94), 3. sukobe s bolesnikom ( $M=1,95)$, (tablica 5).

\begin{tabular}{c|c|}
$\begin{array}{c}\text { Tablica 5. Prikaz tvrdnji s najvećim i najmanjim } \\
\text { prosječnim vrijednostima na razinu stresa }\end{array}$ \\
\hline TVRDNJE (N =63) & $\mathrm{M}$ \\
\hline Nedostatan broj djelatnika & 3,94 \\
\hline Administrativni poslovi & 3,76 \\
\hline Neadekvatna osobna primanja & 3,73 \\
\hline 24- satna odgovornost & 1,65 \\
\hline Strah od izloženosti citostaticima & 1,94 \\
\hline Sukobi s bolesnikom & 1,95 \\
\hline
\end{tabular}

\section{Rasprava}

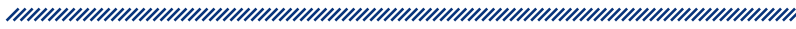

Rezultati istraživanja stresa na radu fizioterapeuta zaposlenim u Kliničkom bolničkom centru Zagreb (KBC Zagreb) ukazuju da fizioterapeuti doživljavaju stres na radu ispod prosjeka.

U odnosu na udio spola u uzorku, zastupljenost žena trostruko je veća od muškaraca (49/63 žena i 14/63 muškaraca). Rezultati t-testa pokazuju da u prosjeku žene u nešto većoj mjeri procjenjuju razinu stresa od muškaraca te da je rezultat u granici razine značajnosti no nije statistički značajan ( $t=-1,931 ; p=0,058$ ). Prema literaturi, žene su podložnije stresu na radu zbog svoje višestruke uloge u privatnom i profesionalnom životu te se pokazalo da žene doživljavaju veći stres sa simptomima iscrpljenosti, manjka kontrole i teškoće sna. ${ }^{15-17}$

Dobivene korelacije pokazuju da nema statistički značajne povezanosti stresa i dobi te ukupnog radnog sta-

\begin{tabular}{|c|c|c|c|c|}
\hline \multicolumn{4}{|c|}{ Tablica 4. Prikaz analize korelacija za određene demografske podatke } \\
\hline & & DOB & UKUPNI STAŽ & $\begin{array}{c}\text { STAŽ NA } \\
\text { TRENUTAČNOM } \\
\text { RADNOM MJESTU }\end{array}$ \\
\hline STRES & $\mathrm{r}$ & 0,15 & 0,17 & 0,10 \\
$(\mathrm{~N}=63)$ & $\mathrm{p}$ & 0,25 & 0,18 & 0,45 \\
\hline
\end{tabular}


ža i radnog staža na trenutačnom radnom mjestu fizioterapeuta u KBC-u Zagreb. Ovi podaci ukazuju nam na praksu koja prepoznaje da radno mjesto treba prilagoditi sposobnostima zaposlenika, kako tjelesnim tako i mentalnim.

Najveći prosječan ukupni indeks stresa vidljiv je u kategoriji organizacije i iznosio je 3,45 \pm 0,87 bodova, dok je najmanji prosječan ukupni indeks stresa vidljiv u kategoriji javne kritike i iznosio je 2,18 \pm 0,08 bodova.

Iz izračuna prosječnih vrijednosti stresa u radu fizioterapeuta po pojedinim tvrdnjama najveći je izvor stresa u kategoriji organizacije posla (nedostatan broj djelatnika, $M=3,94)$, nakon toga slijedi kategorija profesionalnih zahtjeva (administrativni poslovi, $M=3,76$ ), a potom kategorija iz financijskog područja (neadekvatna osobna primanja, $M=3,73)$. Najmanji izvori stresa $u$ radu fizioterapeutima predsatvlja tvrdnja iz kategorije profesionalnih zahtjeva (24 - satna odgovornost, $\mathrm{M}=$ $1,65)$, potom slijede tvrdnje iz kategorije straha i sukoba (strah od izloženosti citostaticima i sukobi s bolesnikom) (tablica 6).

\begin{tabular}{|c|c|c|c|}
\hline $\begin{array}{c}\text { Tablica 6. Prikaz ukupne prosječne } \\
\text { vrijednosti stresa po pojedinim } \\
\text { kategorijama }\end{array}$ \\
\hline KATEGORIJE (N =63) & MIN. & MAKS. & M \pm SD \\
\hline ORGANIZACIJA & 1,40 & 5,00 & $3,45 \pm 0,88$ \\
\hline JAVNA KRITIKA & 1,00 & 4,57 & $2,19 \pm 0,89$ \\
\hline OPASNOSTI & 1,00 & 5,00 & $2,32 \pm 1,09$ \\
\hline SUKOBI & 1,00 & 4,50 & $2,31 \pm 0,92$ \\
\hline PROFESIONALNI ZAHTJEVI & 1,40 & 5,00 & $3,25 \pm 1,07$ \\
\hline
\end{tabular}

Iz rezultata je razvidno da su ispitanicima izvor stresa ponajprije organizacijski problemi, a na njih se pak nadovezuju novi profesionalni zahtjevi. Zakon o fizioterapijskoj djelatnosti obvezuje fizioterapeute na svakodnevno vođenje fizioterapeutske dokumentacije s izradom plana i cilja fizioterapije, kao i evaluacije stanja bolesnika te na cjeloživotno trajno usavršavanje. ${ }^{18}$

Ovim se istraživanjem pokazalo da nedostatan broj djelatnika i novi profesionalni zahtjevi zauzimaju vodeće izvore stresa u radu fizioterapeuta.

Istraživanje provedeno u Poljskoj na fizioterapeutima ( $N=200)$ dokazalo je da slabija financijska situacija među ženama i nedostatak slobodnog vremena kod muškaraca mogu izazvati osjećaj preopterećenosti na radu te da osjećaj zadovoljstva i sreće među ispitanicima smanjuje osjećaj preopterećenosti na radu. ${ }^{17}$
Loša organizacija rada stresor je koji navode zdravstveni djelatnici i u razvijenim zemljama svijeta. Rezultati istraživanja ukazuju na mali broj djelatnika kao jedan od najvećih problema u zdravstvu što je veliki problem i u drugim zemljama. Zdravstveni djelatnici opisuju se kao skupina kod koje je stres na radu visok, te je očuvanje njihove radne sposobnosti od posebne važnosti, kako za njih same, tako i za širu društvenu zajednicu zbog značaja i osjetljivosti posla koji obavljaju. ${ }^{19-21}$

Istraživanje provedeno kod svih zaposlenika ( $\mathrm{N}=101) \mathrm{u}$ Centru za hitnu medicinu KBC-a Zagreb, u dobi između $18 \mathrm{i}$ 65 godina, koji rade na radnom mjestu djelatnika u integriranoj hitnoj bolničkoj službi (pomoćni medicinski djelatnici, administrativno osoblje, medicinske sestre i tehničari, liječnici) pokazuje kao vodeće stresore preopterećenost poslom (67\%), nedostatan broj djelatnika (57\%), neadekvatna materijalna sredstva za rad (50 \%), lošu organizacija posla (49\%), izloženost neprimjerenoj javnoj kritici (47 $\%$ ), pogrešno informiranje bolesnika od strane medija (47 $\%$ ), noćni rad (46\%), suočavanje s neizlječivim bolesnicima (43\%) te neadekvatna osobna primanja (42\%).22

Istraživanje kako i koliko stres na radu utječe na radnu sposobnost zdravstvenih djelatnika u bolnicama u Republici Hrvatskoj provedeno 2010. godine ( $N=1856)$ na zdravstvenim djelatnicima koji su bili zaposleni u pet zagrebačkih bolnica na 19 različitih specijalističkih odjela, pokazuje da dvije trećine prepoznaje svoje radno mjesto kao izvor stresa. Organizacija rada i financijska ograničenja za rad najveći su izvor stresa. Svi stresori, spol i dob značajno su negativno povezani s pokazateljem radne sposobnosti zdravstvenih djelatnika. Na radnu sposobnost liječnika značajno negativno utječu organizacijska i financijska pitanja, a na radnu sposobnost medicinskih sestara/tehničara dodatno utječu sukobi i loša komunikacija te smjenski rad.2,23

Istraživanje provedeno u zdravstvenim ustanovama Republike Hrvatske u kojem su ispitanici zdravstveni djelatnici ( $N=1421$ ) iz pet zdravstvenih profesija: medicinske sestre/medicinski tehničari ( $N=1085)$, fizioterapeuti $(\mathrm{N}=77)$, medicinsko laboratorijski tehnolozi ( $\mathrm{N}$ $=140)$, primalje $(\mathrm{N}=42)$ i radiološki tehnolozi $(\mathrm{N}=77)$ s prostora Republike Hrvatske ukazuju da je mali broj djelatnika jedan od najvećih problema u zdravstvu ${ }^{23}$, što je prepoznato i u istraživanju na fizioterapeutima.

U hrvatskoj literaturi nedostaju istraživanja provedena o utjecaju stresa na radu u fizioterapeuta. Najviše istraživanja ovakvog tipa provedeno je na liječnicima i medicinskim sestrama, dok su ostale profesije svrstavane pod „ostalo zdravstveno osoblje”., 8, 16, 22, 23 
Istraživanje provedeno u Portugalu gdje su ispitanici bili fizioterapeuti $(\mathrm{N}=55)$ pokazalo je da većina fizioterapeuta smatra da su povremeno pod stresom na poslu (35\%) ili su pod stresom (36\%) zbog posla, a da je njihova učinkovitost u rješavanje stresa bila umjereno učinkovita (46\%) ili učinkovita (42\%). Pitanja povezana s nedostatkom profesionalne autonomije, nedostatkom organizacije u hijerarhijskom zapovjednom lancu, nedostatkom stručnog i društvenog priznanja, dezorganizacijom u izvršenju radnih zadataka i međuljudskim sukobima s pretpostavljenima identificirana su kao glavni izvori stresa. ${ }^{19}$

U suvremenom svijetu postoji tendencija sve češće primjene mjera tercijarne prevencije. Dobar poslodavac oblikuje i upravlja poslom na način da izbjegava uobičajene rizične čimbenike i time onemogućuje predvidljive probleme. Pojam prevencija stresa na poslu uključuje dva pristupa:

1. mijenjanje pojedinca uz pomoć treninga za upravljanje stresom $\mathrm{i}$

2. smanjenje stresa promjenom organizacije posla (otklanjanje stresora). ${ }^{2}$

\section{Zaključak}

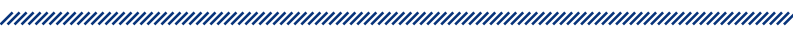

$\mathrm{Na}$ temelju rezultata dobivenih istraživanjem može se zaključiti da su fizioterapeuti procijenili prosječne potencijalne izvore stresa nisko ili umjereno stresno.

Vidljivo je da u žena postoji trend veće razine stresa, iako nije dobivena statistički značajna razlika.

Fizioterapeuti prepoznaju sljedeće specifične stresore na svojim radnim mjestima: nedostatan broj djelatnika, administrativni poslovi i neadekvatna primanja.

Na skali intenziteta stresa najjače se prepoznaju oni povezani s organizacijom rada i financijskim ograničenjima.

Razina stresa povezana s dobi, ukupnim radnim stažem te radnim stažem na trenutačnom radnom mjestu nije statistički značajna, kao ni razina stresa povezana s radnim mjestom (poliklinika, odjeli, intenzivne jedinice). Također, razina stresa nije povezana sa stupnjem obrazovanja fizioterapeuta.

Bilo bi korisno provesti slično istraživanje na nacionalnoj razini kako bi se mogao dobiti bolji uvid u najčešće izvore stresa u fizioterapeuta te njihov odnos $\mathrm{s}$ različitim obilježjima ispitanika. Također, uključivanje i drugih varijabli (npr. samoefikasnost, perfekcionizam, kvaliteta života) može pridonijeti boljem razumijevanju doživljaja stresa na radnom mjestu i dati smjernice za planiranje preventivnih mjera.

\section{Referencije}

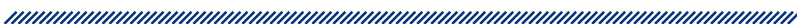

1. Jokić-Begić N. Sociologija i prostor. Institut za društvena istraživanja u Zagrebu. 46 2008; 179 (1): 101- 105.

2. Juras K, Knežević $B$, Golubić R, Milošević M, Mujstabegović J. Stres na radu: mjere prepoznavanja, rješenja i prevencija. SG. 2009; 51 (2): 121-126. Dostupno na: http:// hrcak.srce.hr/index.php?show=clanak\&id_clanak_jezik $=60525$ (pristupljeno 15.10.2017.)

3. Brkić l, Rijavac M. Izvori stresa, suočavanje sa stresom i životno zadovoljstvo učitelja razredne nastave i predmetne nastave. Napredak. 2011; 152(2): 211-225. Dostupno na: https://hrcak.srce.hr/index.php?show=clanak\&id_ clanak_jezik=123100 (pristupljeno 20.5.2019.).

4. Caruso CC, Bushnell T, Eggerth D, Heitmann A, Kojola B, Newman K, et al. Long Working Hours, Safety, and Health: Toward a National Research Agenda. Am. J. Ind. Med. 2006; 49: 930-942. Dostupno na: https://www.ncbi.nlm. nih.gov/pubmed/16948157\# (pristupljeno 10.10.2017.).

5. McCunney RJ. Healthy Workforce/Healthy Economy: The Role of Health, Productivity, and Disability Management in Addressing the Nation's Health Care Crisis. JOEM.2009; 1(51): 114-119. Dostupno na: https://www.ncbi.nlm.nih. gov/pubmed/?term=McCunneyHealthy+Workforce $\% 2 F$ Healthy+Economy\%2C\# (pristupljeno 6.11.2017.).

6. Stranks J. Stress at Work: Management and Prevention. Burlington: Elsevier Butterworth-Heinemann; 2005.

7. EU-OSHA - European Agency for Safety and Health at Work. How to tackle psychosocial issues and reduce work-related stress. Report to the European Agency for Safety and Health at Work, Office for Official Publications of the European Communities, Luxembourg, 2002.

8. Strapajević D. Procjena utjecaja rada u integriranoj bolničkoj hitnoj službi na zdravlje i radnu sposobnost djelatnika. SG/NJ. 2015; 20: 231-239. Dostupno na: http:// hrcak.srce.hr/index.php?show=clanak\&id_clanak_ jezik=220005 (pristupljeno 6.11.2017.)

9. Al-Imam DM, Al-Sobayel HI. The Prevalence and Severity of Burnout among Physiotherapists in an Arabian Setting and the Influence of Organizational Factors: An Observational Study. J Phys Ther Sci. 2014; 26(8): 1193-8. Dostupno na: https://www.ncbi.nlm.nih.gov/ pubmed/25202179\# (pristupljeno 6.11.2017.).

10. Saganha JP, Doenitz C, Greten T, Efferth T. Qigong therapy for physiotherapists suffering from burnout: 
a preliminary study. J Integr. Med. 2012; 11(10): 12331239. Dostupno na: https://www.ncbi.nlm.nih.gov/ pubmed/?term=saganha+JP\# (pristupljeno 30.11.2016.).

11. Serrano Gisbert MF, de Los Fayos EJ, Hidalgo Montesinos MD. Burnout in Spanish physiotherapists [J]. Psicothema. 2008; 20(3): 361-368. Dostupno na: https://www.ncbi.nlm. nih.gov/pubmed/18674428\# (pristupljeno 30.11.2017.).

12. Campo MA, Weiser S, Koenig KL. Job Strain in Physical Therapist. Phys Ther. 2009; 89(9): 946-956. Dostupno na: https://www.ncbi.nlm.nih.gov/pubmed/19608632\# (pristupljeno 30.11.2016.).

13. Lučanin D. Mjere prevencije i sprečavanja štetnih posljedica stresa. SG. 2014; 56(3): 223-234. Dostupno na: http://hrcak.srce.hr/index.php?show=clanak\&id_clanak_jezik=188648 (pristupljeno 5.10.2017.).

14. Milošević M. Izrada mjernog instrumenta stresa na radnom mjestu bolničkih zdravstvenih djelatnika i procjena njegove uporabne vrijednosti. Doktorska disertacija: Zagreb; Sveučilište u Zagrebu, Medicinski fakultet; 2010.

15. Uvodić Vranić LJ. Kako se dobro posvađati? Zagreb: Profil International; 2008.

16. Sindik J, Perinić Lewis A, Novokmet N, Havaš Auguštin D. Usporedba stresa i mentalne čvrstoće kod medicinskih sestara i policijskih službenika. SG. 2014; 56(3): 213-221. Dostupno na: http://hrcak.srce.hr/index.php?show=clanak\&id_clanak_jezik=188646 (pristupljeno 30.11.2017.).

17. Sliwinski Z, Starczynska M, Kotela I, Kowalski T, KrysNoszczyk K, Lietz-Kijak D, et al. Life satisfaction and risk of burnout among men and women working as physiotherapists. International Journal of Occupational Medicine and Environmental Health. 2014; 27(3): 400-412. Dostupno na: https://www.ncbi.nlm.nih.gov/ pubmed/24820030\# (pristupljeno 30.11.2017.).

18. Hrvatski sabor. Zakon o fizioterapeutskoj djelatnosti NN 120/08. Narodne novine. 2008.

19. Santos MC, Barros L, Carolino E. Occupational stress and coping resources in physiotherapists: a survey of physiotherapists in three general hospitals. Physiotherapy. 2010; 96: 303-310. Dostupno na: https://www.ncbi.nlm. nih.gov/pubmed/21056165\# (pristupljeno 30.11.2017.).

20. Pavlakis A, Raftopoulos V, Theodorou M. Burnout syndrome in Cypriot physiotherapists: a national survey [J]. BMC Health Serv Res. 2010; 10: 63. Dostupno na: https:// www.ncbi.nlm.nih.gov/pubmed/20222948\# (pristupljeno 6.1.2017.).

21. Bono JE, Glomb TM, Shen W, Koch AJ. Building positive resources: Effects of positive events and positive reflection on work stress and health. Academy of Management Journal. 2013; 6(56): 1601.

22. Strapajević D. Procjena utjecaja rada u integriranoj bolničkoj hitnoj službi na zdravlje i radnu sposobnost djelatnika. Diplomski rad. Zagreb: Sveučilište u Zagrebu, Medicinski fakultet; 2014.

23. Buljubašić A. Sindrom sagorijevanja među zdravstvenim djelatnicima. Diplomski rad. Split; Sveučilište u Splitu; 2015. 


\section{WORK-RELATED STRESS IN PHYSIOTHERAPISTS}

1,2 Aleksandra Kraljević

2 Melita Rukavina

1,2 Nikolino Žura

1 University Hospital Center Zagreb, Croatia

2 University of Applied Health Sciences Zagreb, Croatia

Stress has been the focus of many research in technical, biomedical and social sciences and humanities. Every field has its own view on stress, therefore, there are many definitions of stress in contemporary literature. Stress is considered as one of the most important sources of psychophysical, work and organisational problems of employees. It is in the second place of workers' health problems in the EU with women being more prone to work-related stress than men. It is one of the biggest causes of professional diseases and absenteeism in the world and one of the leading economic problems in developed countries.

The aim of this study is to identify the most common sources of stress in physiotherapists and examine the relationship between overall stress experience and some sociodemographic characteristic.

Subjects were 65 physiotherapists from the Clinical Hospital Centre Zagreb, of the average age of 42,8 years. We used The Occupational Stress Questionnaire for Hospital Health Care Workers.

The results indicate that physiotherapists experience low to moderate levels of work-related stress. There were no significant correlations between the levels of stress, age and years of practice.

We can conclude that overall stress experience and sociodemographic characteristics are not related. The most common stressors in physiotherapists are those related with work organisation and financial constraints, which is in agreement with other research on work-related stress.

Keywords: stress, work-related stress, physiotherapists 